\title{
Educación inclusiva hoy: sentido y sensibilidades. Entrevista a Ángeles Parrilla
}

\section{Inclusive education today. Sense and sensibilities. Interview with Ángeles Parrilla}

Ester Caparrós Martín*, Mayka García García**, J. Eduardo Sierra Nieto***

Recibido: 26 de enero de 2021 Aceptado: 26 de enero de 2021 Publicado: 31 de enero de 2021

To cite this article: Caparrós, E., García, M. y Sierra, J. E. (2021). Educación inclusiva hoy: sentido y sensibilidades. Entrevista a Ángeles Parrilla. Márgenes, Revista de Educación de la Universidad de Málaga, 1 (2), 226-230

DOI: http://dx.doi.org/10.24310/mgnmar.v2i1.11696

URL: https://www.youtube.com/watch?v=tlohxMTWLL8

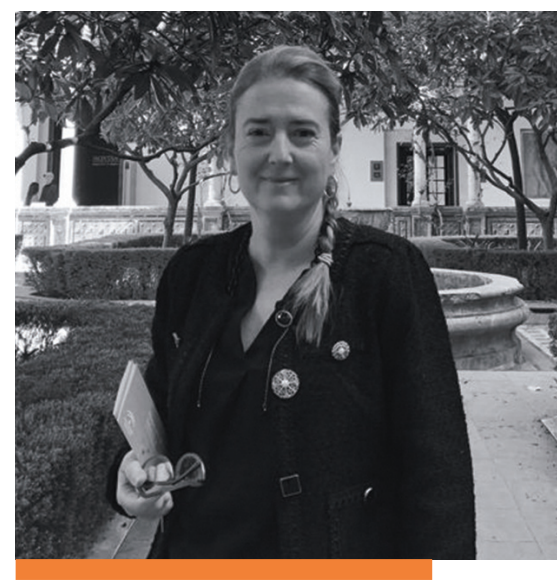

Ángeles Parrilla Latas

\section{RESUMEN}

Ángeles Parrilla Latas es Catedrática de Didáctica y Organización Escolar en la Universidad de Vigo (España). Se trata de unas de las referentes actuales de la educación inclusiva en el panorama estatal y europeo. En la entrevista para Márgenes, Ángeles nos va acercando — desde su recorrido y experiencia personal, académica y profesional — a una noción de educación inclusiva que se va construyendo bajo la idea de proceso. Asimismo, desde su dimensión investigadora nos abre un abanico de intereses que, bajo el denominador común de la práctica docente en los centros educativos, le han ayudado a conformar un pensamiento en torno a la inclusión que hoy nos inspira a muchas, y que tiene que ver con su enfoque como un proyecto de naturaleza comunitaria.

Palabras clave: educación inclusiva; formación del profesorado; proyecto comunitario; redes locales

\section{ABSTRACT}

Ángeles Parrilla Latas is Professor of Didactics and School Organisation at the University of Vigo (Spain). She is one of the current inspirational leaders in inclusive education in Spain and Europe. In the interview for Márgenes, Ángeles brings us closer — from her personal, academic and professional experience - to a notion of inclusive education that is built
*Ester Caparrós Martín 0000-0003-1700-3577

Departamento de Didáctica y Organización Escolar, Universidad de Málaga (España) ester.caparros@uma.es
**Mayka García García 0000-0002-1711-6785

Departamento de Didáctica

Universidad de Cádiz (España)

mayka.garcia@uca.es
***. Eduardo Sierra Nieto 0000-0002-9925-1656 Departamento de Teoría e Historia de la Educación y MIDE, Universidad de Málaga (España) esierra@uma.es 
under the idea of process. Likewise, from her research perspective, she opens up a range of interests which, under the common denominator of teaching practice in educational centers, have helped her to shape a way of thinking about inclusion which today inspires many of us, and which has to do with her community-project approach.

Keywords: inclusive education; teacher education; community project; local networks

\section{BIOGRAFÍA PROFESIONAL}

Ángeles Parrilla Latas es Catedrática de Didáctica y Organización Escolar en la Universidad de Vigo $^{1}$ (España) y unas de las referentes actuales de la educación inclusiva en el panorama estatal y europeo. A través de una biografía narrada en primera persona y construida de manera siempre coral - como enfatiza-, nos cuenta acerca de su práctica profesional en los diferentes escenarios vividos, acercándonos así al proceso de desarrollo de la inclusión escolar en nuestro territorio.

Durante la entrevista, Ángeles nos invita a pensar en un hecho paradójico, a través de una reflexión sobre los debates actuales en torno a la inclusión, y que emergen de la aprobación de la LOMLOE; y es que muchas de las argumentaciones, las posiciones e incluso los miedos que se reflejan actualmente son los mismos a los que antaño, en los orígenes de la integración, se enfrentaban el profesorado y la misma comunidad educativa.

Para Ángeles, si algo está claro, es que la educación inclusiva no es un modelo técnico que se pueda implantar sin más, si no hay antes un deseo por repensar y cuestionar la concepción más extendida de la educación y del sistema escolar. Aunque los planteamientos sobre inclusión se presentan desde sus inicios como una utopía, esta noción se ha ido construyendo bajo la idea de proceso, lo que ha supuesto, según nos advierte la autora, la consolidación de su verdadero sentido ético. Un sentido, que se ha ido elaborando en aquellas prácticas educativas respetuosas con la diversidad,

\section{"La educación inclusiva no es un modelo técnico que se pueda implantar sin más [...]"}




\section{"La inclusión [...] requiere reconocer la necesidad de trabajar colaborativamente ante la incertidumbre que supone el reto educativo [... $]^{\prime \prime}$}

que atienden y entienden las diferencias como una oportunidad para repensar los escenarios escolares a todos los niveles.

Acerca de esto, rescatamos tres ideas importantes a las que hace mención la autora, a la luz de sus planteamientos: en primer lugar, la idea de la inclusión como un derecho humano, lo que significa que como tal "nunca podremos negociarla". En segundo lugar, nos cuenta que la inclusión no hace referencia solo a colectivos o determinadas personas en situación de disCapacidad, sino que requiere más bien, hablar y reflexionar sobre la calidad de los entornos educativos que organizamos y ofrecemos en las escuelas; entornos en los que "todos tienen derecho a estar, a aprender y a participar". Por último, una tercera idea relacionada con la participación: "tenemos que poder ser escuchados, tenemos que poder ser tenidos en cuenta, implicarnos...”. Participar es, en palabras de Ángeles, "brindar la oportunidad de que a todos los niños y todas las niñas se les reconozca dentro de las aulas".

Respecto de estas ideas señala otra cuestión que, a nuestro modo de ver, refleja la realidad de las aulas actuales con relación a una noción de inclusión no siempre clara. Tal y como sostiene Ángeles, en las escuelas se ha ido dando forma a una idea de inclusión que se contradice con ese sentido de derecho para todas y todos. Así, nos habla de cómo se han creado diferentes recursos, itinerarios educativos paralelos, aulas especificas en los centros ordinarios; todo un catálogo de herramientas de una inclusión que excluye y es selectiva, y "que realmente ha supuesto poner límites a esa idea de inclusión".

Como tensión, la autora reflexiona sobre el tipo de cultura docente en la que nos hemos formado, aludiendo a que se trata de un modelo de profesional muy individual: "un profesor sabe como tiene que hacer las cosas, lo controla todo". Pero la inclusión demanda un proceso cualitativamente diferente, incluso procesualmente contrario; requiere reconocer la necesidad de trabajar colaborativamente ante la incertidumbre que supone el reto educativo, y siempre desde la reflexión conjunta y el diálogo. Esto solicita un cambio 
de perspectiva que moviliza la idea de trabajo en equipo (sumar esfuerzos individuales) para convertirlo en trabajo colaborativo (responsabilidad e implicación compartida).

Asimismo, como reto, destacamos lo que señala acerca de la necesidad de pensar las aulas de manera distinta a como la pensamos habitualmente. Los espacios escolares nos hablan de la concepción educativa, por eso, "un aula no puede ser un grupo de $23+2$ niños". Se trata de transformar la organización del aula, de cómo enseñamos atendiendo a cómo aprenden las niñas y los niños; pues, como bien expresa Ángeles "es mucho más rico un entorno escolar donde todas las alumnas y todos los alumnos aprenden de distintos modos, que uno igual en el que todos vayan al unísono”. Y para que la inclusión no se convierta solo en un proyecto académico centrado en la mejora de los aprendizajes individuales de las niñas y los niños, Ángeles señala una idea que nos parece esencial: pensar la inclusión como proyecto social, afirmando con fehaciente confianza, que para hacer la escuela inclusiva "hay que tener en cuenta a la comunidad". Es más, que desde las escuelas tenemos que dejar de pensarnos como entidad central de un sistema, para reconocernos como elementos de este, lo que supone el paso a una concepción de red socioeducativa.

Ese enfoque, que entiende la inclusión como proyecto de naturaleza comunitaria, ha ayudado a ir conformando un pensamiento en torno al tema que inspira a muchas y muchos profesionales de la educación. Asimismo, la formación del profesorado, los miedos insertos en la práctica profesional, la comprensión de la exclusión desde las voces de jóvenes, de niñas y de niños, la articulación de prácticas educativas y comunitarias de apoyo y el desarrollo de redes locales, son algunos de los focos que le han posibilitado llegar hasta ahí.

Por último, queremos destacar, como desde una lógica compartida, de sentidos y sensibilidades profundamente ética, Ángeles ilumina hoy una cuestión emergente que necesitamos seguir pensando, la investigación inclusiva. Para la autora, la investigación inclusiva va más allá de la investigación sobre educación

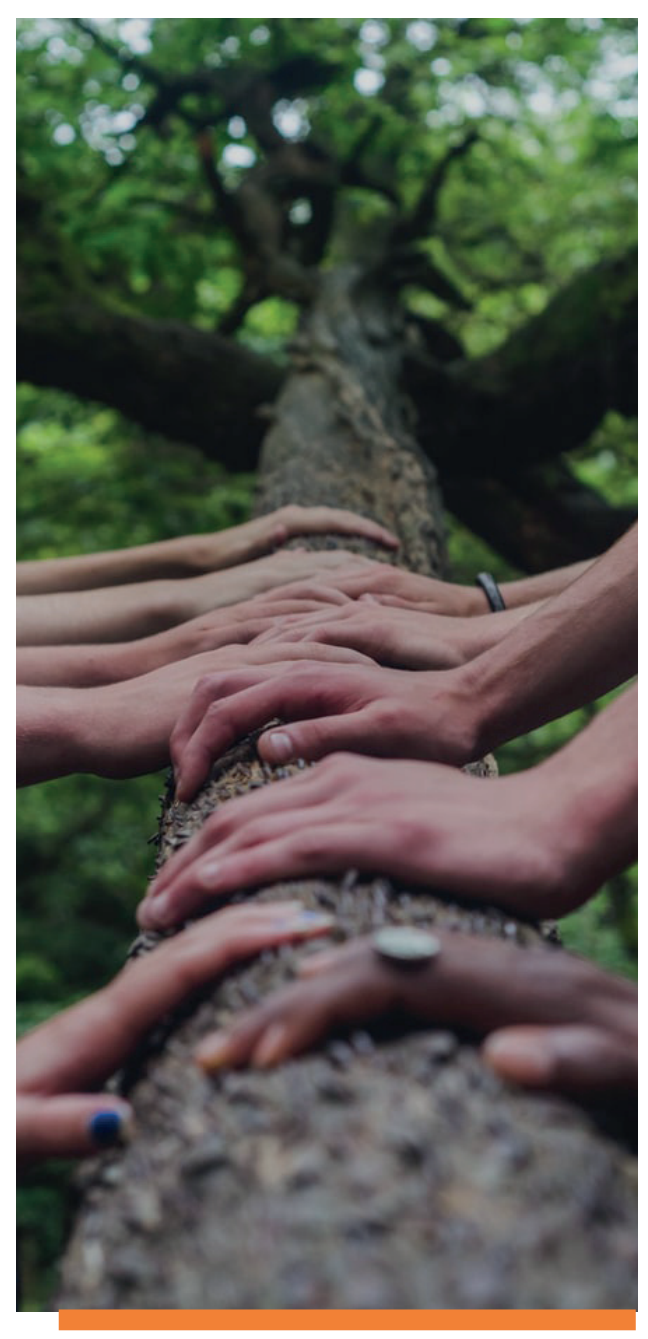

Photo by Shane Rounce on Unsplash 


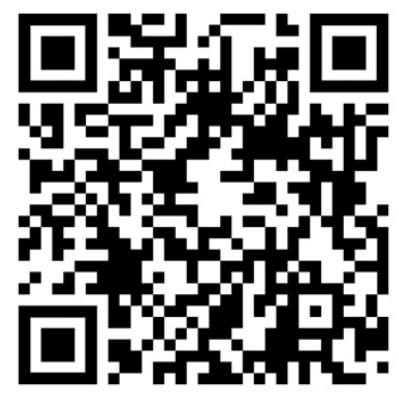

inclusiva, desde el sentido que le permite investigar situándose de un modo comprensivo y respetuoso con el tema de estudio, involucrándose en el propio proceso indagador. La investigación inclusiva permite no solo mirar la educación de otros modos, sino acercarse a los escenarios educativos implicándose con los propios protagonistas. De modo que investigar, es para Ángeles una manera de aprender y compartir las experiencias y las vivencias - y sus sentidos - de aquellos quienes participan en todo aquello que acontece en las prácticas escolares.

Para cerrar, Ángeles hace un llamamiento a la necesidad de reconocer la inclusión como derecho; partir de esa idea, nos abre un camino que lleva mucho ganado en este tema. Y es que, no podemos olvidar que, tal y como expresa la autora, "la inclusión es un modo de vivir, una manera de vivir la vida”. 